\title{
Klaus Neitmann
}

\section{Die Landesordnungen des Deutschen Ordens in Preußen im Spannungsfeld zwischen Landesherrschaft und Ständen}

Die nachfolgende Untersuchung ${ }^{1}$ beschäftigt sich mit denjenigen Quellen, die nach dem Vorbild der grundlegenden, 1878-1886 erschienenen Edition der „Acten der Ständetage Preußens unter der Herrschaft des Deutschen Ordens“ durch Max Toeppen in die wissenschaftliche Literatur als Landesordnungen eingegangen sind. Zwar nennen sich in der Sprache der Quellen bestimmte landesherrliche Regelungen in Preußen erst seit dem 16. Jahrhundert üblicherweise Landesordnung, lateinisch constitutio provincialis, aber da sie in unmittelbarer Kontinuität zu inhaltsgleichen oder inhaltsähnlichen Anweisungen aus dem späten 14. und dem 15. Jahrhundert stehen, ist man berechtigt, auch schon für die frühere Zeit diesen Ausdruck zu verwenden. Wenn sich die älteren Texte selbst auf den Begriff bringen - was eher die Ausnahme als die Regel ist -, bezeichnen sie sich als (us)saczunge des Hochmeisters, als des berren bomeisters und des landes wilkore oder wilkor des landes oder regiment und wilkur unsers berren bochmeisters; die letzten drei Überschriften finden sich in verschiedenen Handschriften für dieselbe Landesordnung von $1420^{2}$. In den 30er und 40er Jahren des 15. Jahrhunderts fordert man wiederholt die Abfassung eines besseren „Regimentes" für das Land, und dabei taucht auch das Wort Gesetz auf. 1441 schlug Hochmeister Konrad von Erlichshausen der Ritterschaft als einen Weg, um die Übergriffe der Femegerichtsbarkeit auf Preußen zu verhindern, vor, das wir setczeten daruff wilkor adir gesetcze, das nymandt mit suttbem rechte den andren sulde drangen ${ }^{3}$. Die Landesordnungen einfach mittels eines eindeutigen zeitgenössischen Begriffs als eine bestimmte Art von Rechtsvorschriften klar einzugrenzen, ist bei dieser vielfältigen Ausdrucksweise ausgeschlossen. Die Frage, was Landesordnungen sind, läßt sich eingangs trotzdem nicht umgehen, sofern man für die Antwort nicht eine scharfumrissene De-

${ }^{1}$ Wesentliche Anregungen für die Bearbeitung des Themas hat der Verf. von Herrn Prof. Dr. Reinhard Wenskus (Göttingen) und dessen vor nahezu zehn Jahren abgehaltenem Seminar über die Landesordnungen des Deutschen Ordens in Preußen empfangen. Ihm sei dafür auch an dieser Stelle herzlichst gedankt.

2 Acten der Ständetage Preußens unter der Herrschaft des Deutschen Ordens, hrsg. v. Max Toeppen, Bd.1-3 (Leipzig 1878-1882, Ndr. Aalen 1973-1974), s.v. Regiment, Willkür in den Sach- und Wortregistern. Landesordnung von 1420: Bd. 1, Nr. 286, S. 348 mit Fußnote a; im folgenden zitiert: AST.

3 AST 2, Nr. 253, S. 381. 
finition verlangt, die die individuellen historischen Erscheinungen doch nicht hinreichend zu erfassen vermag, sondern sich mit einer ungefähren Beschreibung dessen begnügt, wovon überhaupt gehandelt werden soll.

Den Inhalt der verschiedenen kürzeren oder längeren Ordnungen knapp zusammenzufassen, ist wegen der Verschiedenartigkeit der angesprochenen Materien nahezu unmöglich. Zur allgemeinen Charakterisierung wird man nicht viel mehr sagen können, als daß Probleme des wirtschaftlichen, sozialen, rechtlichen und kirchlichen Lebens sowohl der Bürger, Kaufleute und Handwerker in den Städten als auch der Bauern und des Gesindes auf dem Lande sowie die Beziehungen zwischen Stadt und Land untereinander und zur Landesherrschaft im Sinne des oft beschworenen ,gemeinen Nutzens“ geregelt werden ${ }^{4}$. Zwar zeichnen sich deutlich Schwerpunkte ab, aber prinzipiell ist keiner Frage des sozialen Daseins die Aufnahme in die Landesordnungen verwehrt. Als man 1444/45 über ein neues Regiment beriet, trugen viele Städte und Gebiete den Amtsträgern des Ordens geradezu einen Katalog ihrer individuellen Beschwerden vor, teils allgemeiner Natur, teils aber auch sehr spezieller Art, so daß sie offenkundig davon ausgingen, auch ihre aktuellen lokalen Anliegen könnten auf dem Wege über eine allgemein verbindliche Vorschrift erfüllt werden ${ }^{5}$. Denn als zweites konstitutives Element der Landesordnungen kommt hinzu, daß sie für das gesamte Ordensland oder, wenn dies aus noch näher zu erörternden Gründen nicht zutrifft, dann zumindest für einen großen Landesteil gelten ${ }^{6}$. Wenn auch manche Verordnungen nur bestimmte Berufsgruppen betreffen, so wenden sie sich doch nicht nur an die Kannengießer und Gewandschneider in Danzig, Elbing oder Thorn, sondern überall im Lande. Durch den Anspruch der Normen auf Allgemeingültigkeit lassen sich die Landesordnungen noch am ehesten von den an einen einzelnen Empfänger oder einen begrenzten Empfängerkreis gerichteten Privilegien unterscheiden, wenn auch in einer grauen Übergangszone die Zuweisung im Einzelfall schwerfällt ${ }^{7}$.

Neben dem Inhalt und dem Geltungsbereich ist schließlich noch der Aussteller zu

${ }^{4}$ Noch unbestimmter definiert $W$. Brauneder, in: Handwörterbuch zur deutschen Rechtsgeschichte, Bd. 2 (Berlin 1978) Sp. 1406: „Landesordnungen im spezifischen Sinne sind Gesetzeswerke, die das Recht des neuzeitlichen Territorialstaates in einer möglichst alle Rechtsgebiete umfassenden Kompilation festhalten wollen, wobei aber keine vollständige Regelung der einzelnen Teilgebiete angestrebt wird, sondern eher nur die Klarstellung besonders wichtiger oder aktueller Fragen." Ebd. weitere Lit. Die älteren Forschungen zu den Landes- und Polizeiordnungen des 15./16. Jahrhunderts faßst zusammen Fritz Hartung, Deutsche Verfassungsgeschichte vom 15. Jahrhundert bis zur Gegenwart (Stuttgart ${ }^{7}$ 1959) 64-69.

${ }_{5}^{5}$ AST 2, Nr. 385-397.

6 Vgl. Reinhard Wenskus, Das Ordensland Preußen als Territorialstaat des 14. Jahrhunderts, in: Der deutsche Territorialstaat im 14. Jahrhundert I, hrsg. v. Hans Patze (Vorträge und Forschungen 13, Sigmaringen 1970) 347-382, hier $380 \mathrm{f}$.

7 Der Überblick von Armin Wolf, Die Gesetzgebung der entstehenden Territorialstaaten: PreuBen, in: Handbuch der Quellen und Literatur der neueren europäischen Privatrechtsgeschichte, Bd. 1, hrsg. v. Helmut Coing (München 1973) 752-757, leidet darunter, daß er die Vorschriften für die Ordenskorporation, die Privilegien einzelner ständischer Gruppen einschließlich der Stadtrechte und innerstädtischer Willküren, die Rechtsbücher und die von Herrschaft und Ständen vereinbarten Landesordnungen nebeneinander behandelt, ohne sie deutlich voneinander abzugrenzen. 
erwähnen. Es ist in allen eindeutig entscheidbaren Fällen der Hochmeister des Deutschen Ordens. Allerdings gedenkt er in der Narratio regelmäßig des Rates der Prälaten, die in Preußen zur Herrschaft zählen, der Gebietiger, d.h. der obersten Amtsträger des Ordens, und der Städte und des Landes, d.h. der sog. Hauptstädte Thorn, Kulm, Elbing, Danzig, Braunsberg und Königsberg und der Ritterschaft, der Inhaber der großen Dienstgüter des Ordens, und auf der Grundlage der gemeinsamen Übereinstimmung fordert er dazu auf, daß die nachfolgenden Artikel von jedermann beachtet und gehalten werden. Zwei charakteristische Einleitungen seien zitiert. 1425 macht Hochmeister Paul von Rusdorf bekannt, das wir mit gemeynen unsir gebitiger und der stete disser lande rathe syn eyns wurden desse nochgescbreben artikel, und wellen ouch ernstlichen, das dy stete, faste und unvorserlich werden gebalden ${ }^{8}$. Zehn Jahre später heißt es, das wir umbe meynes nutcz und fromen wille disszer lande mit unsir berren disses landes prelaten, gebietiger, lande und stete rathe und vorliebunge sien czu rathe wurden und endlich beslossen baben ${ }^{9}$. In diesen Formulierungen steckt das Problem, das im Mittelpunkt der folgenden Darlegungen stehen soll. Ist die Berufung des Hochmeisters auf den Rat seiner Stände bloß eine nichtssagende Routineformel, eine unverbindliche Floskel, oder verbirgt sich hinter ihr tatsächlich die historische Realität einer ständischen Mitbestimmung ${ }^{10}$ ? Die Beantwortung dieser Frage ist von großer Bedeutung für die Beurteilung der Landesordnungen, sagt doch erst ihre Entstehungsgeschichte etwas aus über die jeweils beteiligten Interessenten und ihre Motive, darüber, von wem die Initiative zu der Regelung ausgegangen ist und welche Absichten und Ziele er damit verfolgt hat. Die Texte der Verordnungen allein geben auf diese Fragen keine über Vermutungen hinausreichenden Antworten; dazu müssen die für das hier zu untersuchende späte 14. und die erste Hälfte des 15. Jahrhunderts reichlich vorhandenen Quellen über die Verhandlungen mit und unter den Ständen herangezogen werden ${ }^{11}$.

${ }^{8}$ AST 1, Nr. 349.

9 AST 1, Nr. 548.

10 Folgt man Lothar Dralle, Der Staat des Deutschen Ordens in Preußen nach dem II. Thorner Frieden (Frankfurter Historische Abhandlungen 9, Wiesbaden 1975) 136f., stellt der 13jährige Krieg zwischen 1454 und 1466 den grundsätzlichen Einschnitt in dieser Frage dar. Vorher - so Dralle mit Hinweis auf die Landesordnungen von 1441 und 1444 - sei von einer Mitwirkung der Stände am Zustandekommen der Landesordnungen nichts bekannt; nach dem 2. Thorner Frieden 1466 seien hingegen die Landesordnungen auf den Tagfahrten von Hochmeister und Ständen beraten und beschlossen worden.

${ }^{11}$ Die Untersuchung kümmert sich bewußt nicht um die rechtshistorische Beurteilung der Landesordnungen, nicht etwa deswegen nicht, weil sie diese Frage geringschätzte, sondern weil dafür die beste Grundlage dadurch geschaffen wird, daß man zunächst das politische Ringen um die Einführung und Durchsetzung von neuen Rechtsordnungen aufhellt und den dahinter stehenden politischen Kräften nachspürt. Úber zentrale rechtshistorische Fragen der spätmittelalterlichen europäischen Gesetzgebung orientiert Wolf (wie A.7) 517-566. Vgl. auch Brauneder (wie A.4). An Hand niederrheinisch-westfälischer Territorien erörtert die Probleme spätmittelalterlicher Gesetzgebung die durch den Reichtum der Gesichtspunkte vorbildliche Untersuchung von Wilbelm Janssen, „... na gesetze unser lande ..... Zur territorialen Gesetzgebung im späten Mittelalter, in: Gesetzgebung als Faktor der Staatsentwicklung, Red. Dietmar Willoweit (Beihefte zu „Der Staat“ 7, Berlin 1984) 7-40; 41-61 Diskussion über Janssens Vortrag. 
Verordnungen von Hochmeistern über einzelne Sachgebiete kommen in größerer Anzahl im letzten Viertel des 14. Jahrhunderts auf. Beispielhaft sei ein Komplex herausgegriffen, die Verhandlungen über die Weichselschiffahrt und die Feststellung des Weichselfahrerrechts. 1375 erließ Hochmeister Winrich von Kniprode mit Rat der Städte, wie es heißt, sechs Artikel über Rechte und Pflichten der Weichselschiffer. U.a. werden darin die Schiffsknechte verpflichtet, das geladene Gut bis auf den Markt zu bringen, widrigenfalls sie mit dem Verlust eines Ohres bestraft werden. Ist das Schiff wegen Eisgangs auf der Weichsel oder aus einem anderen Grunde an der Weiterfahrt gehindert, muß der Schiffsherr mit seiner Besatzung an der Anlegestelle mindestens drei Tage lang ausharren, und die ihm entstehenden Mehrkosten müssen ihm von den Wareneigentümern entsprechend dem Gewicht des jeweiligen Gutes erstattet werden. Bei einem Schiffbruch sollen die Knechte für die Bergung des Gutes ebenfalls entsprechend dessen Gewicht entlohnt werden ${ }^{12}$. Die Bestimmungen haben auf Dauer nicht ausgereicht, um die, wie man wohl aus der drakonischen Strafe schließen darf, heftigen Streitigkeiten zwischen den Kaufleuten und den ihre Güter befördernden Schiffern zu schlichten. Die Fernhandelsstädte fühlten sich insbesondere durch die zusätzlichen Transport- und Lohnkosten beschwert, wenn die Schiffe wegen der zugefrorenen Weichsel oder wegen Schiffbruchs liegenblieben. Außerdem war ungeklärt, wie lange die Schiffsleute während einer solchen Zwangspause Brennholz am Flußufer ohne Bezahlung einsammeln durften. Auf der Tagfahrt am 18. Dezember 1384 wurden die Ratssendeboten beauftragt, zu diesen Punkten die Stellungnahme ihres heimischen Rates einzuholen ${ }^{13}$, und am 23. Januar 1385 verabschiedete Hochmeister Konrad Zöllner von Rotenstein in Marienburg nach Beratungen mit seinen Gebietigern und den städtischen Vertretern eine neue Weichselfahrerordnung ${ }^{14}$, die zunächst die sechs Artikel von 1375 mit geringfügigen Änderungen wiederholte und daran auf der Grundlage der vorgetragenen Klagen drei neue Artikel anfügte, ohne sie also organisch anzuschließen und systematisch in die ältere Ordnung einzuarbeiten ${ }^{15}$. Die Schiffsherren werden aufgefordert, nach drei Tagen ihre Fahrt fortzusetzen, sofern das Eis dies zuläßt, und zwar zu demselben Preis, den sie bei Antritt ihrer Reise zugesagt haben. Den Weichselfahrern wird freies Brennholz für drei Tage zugestanden. Dauert ihr Aufenthalt länger, haben sie das zusätzliche Holz dessen Eigentümern zu bezahlen, nach einer Schätzung, die zwei Leute aus dem nächstgelegenen Dorf vorgenommen haben, doch sind Eichen und Fichten vom Holzschlag für diese Zwecke ausgeschlossen $^{16}$.

12 AST 1, Nr. 17.

13 Die Recesse und andere Akten der Hansetage von 1256-1430, Bd. 2 (Leipzig 1872, Ndr. Hildesheim, New York 1975), Nr. 297, § 10; im folgenden zitiert: HR.

14 Die Einleitung der Ordnung greift auf die für die städtischen Rezesse üblichen Formulierungen zurück (... civitates bos articulos ... cum consensu domini nostri generalis magistri ac aliorum preceptorum in Marienburg de novo statuerunt.), während im ersten Artikel der Hochmeister in subjektiver Form als Aussteller auftritt (Wir sint zu ratbe wurdin mit den stetin als von den schiffin ...) und die Ordnung damit als hochmeisterliches Mandat zu erkennen gibt.

15 Während der Hochmeister im alten Artikel 1 sich in subjektiver Form einführt, ist im neuen Artikel 9 in objektiver Form aus der Sicht der Städte von ihm die Rede (unser bere bomeister).

${ }^{16}$ AST 1, Nr. 22. 
Die Bestimmungen über das Brennholz sind in der Folgezeit immer wieder mißachtet worden und boten daher Anlaß zu beständigen Beschwerden vor dem Hochmeister. Den Schiffern wurde trotz der hochmeisterlichen Vergünstigung allerorten der Holzverbrauch in Rechnung gestellt, so daß sie im Dezember 1394 von Hochmeister Konrad von Jungingen ein besiegeltes Privileg erbaten, um ihre Berechtigung jederman nachweisen zu können ${ }^{17}$. Die Kaufleute litten unter dem Konflikt zwischen den Schiffern und den Holzeigentümern, denn wenn letztere glaubten, es sei Holz über das erlaubte Maß hinaus geschlagen worden, ließen sie zur Gegenwehr das Kaufmannsgut auf den Schiffen pfänden. Daher verlangten im Dezember 1396 die Städte, daß die Schiffsherren auf eigene Kosten die Waren wieder auslösen sollten, und sie luden die beschuldigten Schiffsherren vor die nächste Tagfahrt der Städte vor $^{18}$. Die Schiffsleute erschienen zwar im März 1397, doch verschob man die weitere Behandlung der Angelegenheit bis zur Rückkehr des Hochmeisters von einer Rundreise durch das Land nach Marienburg ${ }^{19}$. Konrad von Jungingen beschränkte sich allerdings im Dezember 1397 darauf, die Bestimmung von 1385 über das Brennholz in einer eigenen Verordnung zu bestätigen ${ }^{20}$. Bei anderen Wünschen der Städte zeigte er sich hingegen entgegenkommender. Er ließ, wie sie es von ihm erbeten hatten, im Dezember 1394 in die Willkür der Schiffsleute einsetzen, daß kein Schiffsknecht den Schiffsherrn oder Steuermann dazu zwingen dürfe, ihm höheren Lohn über die vereinbarte Summe hinaus zu zahlen. Verwundete oder tötete ein Schiffsknecht den Schiffsherrn oder den Steuermann, wurde er mit dem Verlust seiner Hand bzw. mit der Todesstrafe bedroht, im Falle seiner Flucht in die Landesacht getan ${ }^{21}$. Hinsichtlich der Liegefrist der Schiffe bei Eisgang auf der Weichsel erreichten die Städte am 29. April 1397 eine ergänzende Regelung des Hochmeisters. Können die Schiffsherren wegen Eisgangs nach drei Tagen immer noch nicht weiterfahren, müssen sie einen Boten senden an den Bürgermeister von Thorn, sofern sie weichselaufwärts von Mewe liegen, an den Bürgermeister von Danzig oder Elbing, sofern sie weichselabwärts von Mewe liegen, und ihnen die Empfänger der Waren bezeichnen, damit diese ihr Gut abholen; den Boten soll der empfangende Kaufmann entlohnen. Wenn dieser sich nicht innerhalb von vier Tagen nach seiner Benachrichtigung durch den Bürgermeister um sein Gut kümmert, kann der Schiffsherr für den entstandenen Schaden nicht mehr belangt werden ${ }^{22}$.

Die referierten Verhandlungen und Verordnungen reichen an dieser Stelle zu einer ersten Einschätzung aus. Für die Kaufleute in den großen Fernhandelsstädten Thorn, Kulm, Elbing und vor allem Danzig, das am Ende des 14. Jahrhunderts bereits all seine Konkurrenten im Preußenland überflügelt hatte, war es lebenswichtig, daß der Gütertransport auf dem wichtigen Handelsweg vom und ins polnische Hinterland, auf der Weichsel, reibungslos ablief, daß die getroffenen Liefervereinbarungen von den

17 AST 1, Nr. 46.

${ }^{18}$ HR, Bd. 4 (Leipzig 1877), Nr.386, §4.

19 HR 4, Nr. 397, § 16.

20 AST 1, Nr. 53.

${ }^{21}$ AST 1, Nr. 46.

22 HR 4, Nr.398, § 20. 
Transporteuren eingehalten und nicht von Streitigkeiten unter der Schiffsbesatzung oder der Schiffsbesatzung mit anderen, etwa den Eigentümern des Uferholzes, gestört wurden, von Streitigkeiten, die in ihrer Konsequenz nur den Kaufleuten und ihrem Geldbeutel zur Last fielen. An einem einzelnen vertragsbrüchigen Schiffseigner und Schiffsmann mochte man sich dadurch rächen, daß man sie ins Gefängnis warf, aber damit war das grundsätzliche Problem, die beiderseitigen Rechte und Pflichten in einen ausgewogenen Interessenausgleich zu bringen, nicht gelöst, denn die Städte allein konnten ihn den Weichselschiffern nicht aufzwingen. Nichts lag einer straff geführten Landesherrschaft näher, als daß die städtischen Räte die Anliegen ihres Kaufmanns dem Landesherrn, dem Hochmeister und dessen Gebietigern, vortrugen und ihn um Maßnahmen zur Abstellung der Beschwerden ersuchten. Um ihr Ziel, den ungestörten Warenstrom auf der Weichsel, zu erreichen, bewogen die Fernhandelsstädte den Orden dazu, daß er den Schiffsverkehr bestimmten Regeln unterwarf und die Schiffseigner und ihre Besatzungen an bestimmte Normen band.

Wie schon bemerkt, gibt es aus dem letzten Viertel des 14. Jahrhunderts und den ersten Jahren des 15. Jahrhunderts bereits eine beträchtliche Anzahl von hochmeisterlichen Einzelverordnungen, die sich neben Fragen des Handels vornehmlich Problemen des städtischen Handwerks, sei es einzelner Handwerkszweige wie der Goldschmiedekunst oder der Wollweberei, sei es den Beziehungen zwischen Handwerksmeistern und ihren Gesellen, zuwenden ${ }^{23}$. Die erste größere Zusammenfassung von Einzelverordnungen stellt die Landesordnung des Hochmeisters Ulrich von Jungingen von 1408 mit ihren 19 Paragraphen dar ${ }^{24}$, ohne daß freilich darin alle Bereiche der früheren Ordnungen berührt worden wären und ohne daß man sagen könnte, warum ausgerechnet diese und nicht jene frühere Ordnung wiederholt worden ist. Dafür läßt sich genau feststellen, von wem überhaupt der Anstoß zur Abfassung der neuen Landesordnung ausgegangen ist. Auf dem Ständetag vom 6. Mai 1408 hatten die Städte und die Ritter und Knechte dem Hochmeister eine schriftliche Aufstellung ihrer Beschwerden in 12 Punkten übergeben ${ }^{25}$, und ausdrücklich zu deren Abstellung war die Landesordnung bestimmt, wie Ulrich von Jungingen anläßlich ihrer Publikation am 30. November 1408 betonte. Sechs Paragraphen wiederholten bloß entsprechend dem

${ }^{23}$ Vgl. die Übersicht von Max Toeppen, in: AST 1, 16-19.

24 AST 1, Nr. 82.

${ }^{25}$ AST 1, Nr.79. Die Beschwerden sind anschließend vom Hochmeister den preußischen Bischöfen zur Beratung vorgelegt worden, die dazu auch ihre Empfehlungen ausgesprochen haben. Geheimes Staatsarchiv Preußischer Kulturbesitz, Berlin, XX. HA: Historisches Staatsarchiv Königsberg, Ordensbriefarchiv, Nr. 1037; im folgenden zitiert: OBA. Daß es sich um einen „Huldigungstag" gehandelt habe, daß der Huldigungstag zum ersten Mal dem Orden Forderungen unterbreitet habe, daß man sich des bevorstehenden Krieges mit Polen bewußt gewesen sei (so Karol Górski, Die Anfänge der ständischen Vertretung der Ritterschaft im Ordensland Preußen im 15. Jahrhundert, in: Der Deutschordensstaat Preußen in der polnischen Geschichtsschreibung der Gegenwart, hrsg. v. Udo Arnold u. Marian Biskup [Quellen und Studien zur Geschichte des Deutschen Ordens 30, Marburg 1982] 218-236, hier 228 f.), trifft nicht zu. In seiner fragwürdigen Tendenz, die Schwäche der Stände gegenüber dem angeblichen Machtmißbrauch des Ordens herauszustellen, übersieht Górski die zahlreichen Verhandlungen des Ordens mit den Ständen, insbesondere mit den Städten, über deren Wünsche, auch im Bereich der Gesetzgebung, wie sie ausführlich in Toeppens Ständeakten und in den Hanserezessen dokumentiert sind. 
ständischen Wunsch unverändert frühere Erlasse über Schadenersatzforderungen und Entführung von Jungfrauen, vielleicht deswegen, weil sie sich bislang noch nicht wirksam genug erwiesen hatten. In vier weiteren Paragraphen entsprach der Hochmeister den ständischen Forderungen vom 6. Mai. Niemand soll sich dadurch einem schwebenden Gerichtsverfahren entziehen, daß er sich in dem anhängigen Streitfall auf die Herrschaft beruft. Niemand soll von der Herrschaft zum Kauf oder Verkauf von Wolle oder anderer Kaufmannsware gezwungen werden. Rittern und Knechten sollen ihre Fischereirechte in den Seen des Ordens unverkürzt wie bislang bewahrt bleiben. Für die Erntearbeiter werden verschiedene Lohnsätze festgelegt.

Der städtische Rezeß über die Tagfahrt vom 30 . November $1408^{26}$ fügt allerdings noch hinzu: Item boben di vorgeschriben artikel bliben noch etliche gebrechen stende, doruff unser berre bomeister nicbt geantwert bat. Mehrere ständische Klagen waren also in der Landesordnung überhaupt nicht berührt, mit anderen Worten: sie waren vom Hochmeister abgelehnt worden. Die Stände hatten auch darum gebeten, daß die Müller den Mahlpfennig nicht erhöhten - der Mühlenbetrieb war Ordensregel -, daß die Ordensgebietiger nicht Holz aus ihren Wäldern den Rittern und Knechten und ihrem Gesinde zum Verkauf aufdrängten und daß die Diener der Schäffer, der Handelsbeamten des Ordens, nicht stets den Vorrang für sich bei der Schuldeneintreibung beanspruchten. Das ständische Begehren konzentrierte sich, wie man sieht, darauf, daß der Orden aus der Sicht der Stände ungerechtfertigterweise seine Stellung als Landesherr zu Vorrechten im Handels- und Geschäftsverkehr ausnutzte und seine Regale wie das Fischerei- und Mühlenregal zum Nachteil der Stände auslegte ${ }^{27}$. Die Landesordnung von 1408 zeigt damit einen neuen Aspekt. Sie befaßt sich damit, die Rechte von Herrschaft und Ständen auf Feldern, auf denen sie miteinander in Streit liegen, abzugrenzen. Sie ist vom Hochmeister erlassen worden, und diese Feststellung gilt nicht nur in formaler, sondern auch in inhaltlicher Beziehung, in dem Sinne, daß er zwar auf einige ständische Wünsche eingegangen ist, andere aber, weil sie ihm zu sehr die Position des Ordens mit seinem bedeutenden Eigenhandel zu beeinträchtigen schienen, zurückgewiesen hat. Die letzte Entscheidung über den Inhalt der Gesetzgebung hat sich der Orden vorbehalten, und er ist vor der Schlacht von Tannenberg noch mächtig genug, ein solches Werk zu verabschieden, seine Befolgung anzuordnen und die Mißachtung unter Strafe zu stellen ${ }^{28}$.

26 AST 1, Nr.81.

${ }_{27} \mathrm{Zu}$ den Streitigkeiten des 15. Jahrhunderts um die Fischereirechte vgl. Hartmut Boockmann, $\mathrm{Zu}$ den politischen Zielen des Deutschen Ordens in seiner Auseinandersetzung mit den preußischen Ständen, in: JbGMO 15 (1966) 57-104, hier 76-80.

${ }^{28}$ Etwas anders urteilt Górski (wie A.25) 228: „Die Stände ... bekamen auch keine Garantie dafür, daß der Mißbrauch der Gesetze beseitigt werde, auch kein schriftliches Privileg. Dies ist ein Beweis für ihre Schwäche." Der Hochmeister ließ den Ständen auf der Tagfahrt am 30. November 1408 ein schriftliches Exemplar der Landesordnung überreichen, daher wurde sie auch in den städtischen Rezeß der Tagfahrt aufgenommen und ist sowohl in mehreren städtischen Rezeßsammlungen als auch im Ordensbriefarchiv und in der Fortsetzung der Chronik des Johann von Posilge überliefert, so daß ihr genauer Wortlaut allgemein bekannt war. Keine einzige Landesordnung ist in Privilegienform mit dem üblichen Urkundenaufbau abgefaßt worden; die an das ganze Land gerichteten Ordnungen werfen im Hinblick auf die rechtsgültige „Ausfertigung" 
Der wirtschaftlichen und finanziellen Krise, in die der Krieg von 1409/11 und seine Folgen den Orden stürzten, suchte Hochmeister Michael Küchmeister nach 1414 durch den Erlaß vieler neuer Ordnungen beizukommen ${ }^{29}$. Das Münzwesen wurde nach dem Münzverfall infolge der riesigen Kriegsausgaben und Kriegsfolgelasten neu geordnet, in umittelbarem Zusammenhang damit auch das Schuldenwesen, die Begleichung der Schulden in alter und neuer Münze. Honorar- und Lohnsätze für Advokaten, Handwerker, Feldarbeiter und Gesinde wurden festgelegt. Der Förderung des Handels dienten Bestimmungen über einheitliche Maße und Gewichte, über Ausfuhr und Einfuhr von Waren. Schließlich finden sich Maßnahmen zur Wahrung der öffentlichen Sicherheit und gegen unsittlichen Lebenswandel. Die Anstrengungen Küchmeisters gipfelten in der Landesordnung von $1420^{30}$. Sie zieht die Summe der bisherigen gesetzgeberischen Bemühungen des Ordens, indem sie in ihren 86 Artikeln die früheren Einzelverordnungen aus der Zeit vor und nach 1410 einschließlich der Landesordnung von 1408 wieder aufgreift, zusammenfaßt, strafft und zugleich ergänzt und, wenn auch nicht immer in hinreichendem Maße, zu systematisieren versucht. Auf diese Weise entsteht vor dem Leser ein buntes Bild des Lebens und seiner Probleme in Stadt und Land. In den Vorschriften tauchen etwa auf die Gerichtsverhandlungen, die Entführung von Jungfrauen, der Verkehr der Bauern in den Städten, Gesinde, Dienstboten, Tagelöhner mit ihren Lohnsätzen, Handwerker, Münzen, Silberund Goldarbeiten, Zinsen und Rentenkauf, Sicherheit auf den Straßen, Lästerung der Herrschaft, Gültigkeit der Privilegien usw. Auf unsere leitende Frage nach der jeweiligen Beteiligung von Landesherrschaft und Ständen an der Entstehungsgeschichte verweigert die Landesordnung von 1420 leider jede Antwort. Da weder der Text dazu Andeutungen enthält noch begleitende Verhandlungen überliefert sind, kommt man über bloße Vermutungen nicht hinaus, und daß der Entwurf der Ordnung von den Städten ausgegangen sei, wie Max Toeppen behauptet ${ }^{31}$, beruht nur auf der mehr als wackeligen Grundlage einiger Textvarianten in den verschiedenen überlieferten Textrezensionen.

Die nächste umfassende Landesordnung ist bereits sieben Jahre später, im Frühjahr 1427, von Küchmeisters Nachfolger Paul von Rusdorf erlassen worden. Auf ihre Entstehungsgeschichte wirft die Überlieferung ein helleres Licht. Nachdem der Friede vom Melno-See mit Polen-Litauen im Mai 1423 ratifiziert worden war, lebte das Ordensland nach fast zehn Jahren wieder in einem gesicherten Frieden, während vorher

\section{Fortsetzung Fußnote von Seite 65}

und ihre Publikation ganz andere Probleme auf als ein für einen begrenzten Empfängerkreis gedachtes Privileg. Und wenn Górski dem Orden „Mißbrauch“ und „Willkür" vorwirft, unterstellt er damit stillschweigend ohne nähere Ửberprüfung und ohne Belege die Richtigkeit der ständischen Beschwerden. Er bedenkt dabei nicht, daß Orden und Stände in bezug auf die Landesordnungen teilweise unterschiedliche politische Vorstellungen verfolgten, die sich nicht einfach den Kategorien Recht oder Unrecht zuweisen lassen.

29 Vgl. Max Toeppen, in: AST 1, 237 f.; Peter Gerrit Thielen, Die Verwaltung des Ordensstaates Preußen vornehmlich im 15. Jahrhundert, in: Ostmitteleuropa in Vergangenheit und Gegenwart 11 (Köln, Graz 1965) 44-48.

30 AST 1, Nr.286.

31 AST 1, S.361. 
seit 1414 nur ein immer wieder im letzten Augenblick verlängerter ein- oder zweijähriger Waffenstillstand bestanden hatte. Der neue Hochmeister suchte sich, nachdem sich die äußeren Verhältnisse des Ordensstaates so beruhigt hatten, verstärkt der inneren Notlage des Landes anzunehmen und sie zu beseitigen. Im Herbst 1425 wandte er sich außer an die Gebietiger und die Bischöfe auch an die großen und kleinen Städte und die Ritterschaft des Landes mit einer Umfrage nach den gebrechen des landes. Er wollte sich, wie er erklärte, von ihnen darüber beraten lassen, worummb das lant so grossen gebrechen und mannicherley pfloge leydet und sichtiglich appnymppt $t^{32}$. In seinem Schreiben vom 29. September 1425 an Danzig befahl der Hochmeister dem Rat der Stadt, die Ursachen der mißlichen Verhältnisse gründlich zu erörtern und ihm bis zum 25. November schriftlich mitzuteilen ${ }^{33}$; die Frist wird auch für die anderen Empfänger gegolten haben. Drei zufällig erhaltene Antworten belegen, daß die Umfrage tatsächlich durchgeführt worden ist und anscheinend weite Kreise gezogen hat. Die Stadt Mohrungen legte, nachdem der zuständige Komtur von Elbing ihr die hochmeisterliche Weisung mündlich weitergegeben hatte, ausführlich die Probleme des Landes dar ${ }^{34}$. Der Pfarrer von Elbing unterhielt sich, bevor er seine schriftliche Antwort an den Hochmeister aufsetzte, mit anderen Priestern und mit Ehrbarleuten über die Gründe der wirtschaftlichen Schwierigkeiten ${ }^{35}$. Die samländischen Domherren übermittelten der Marienburg die Klagen der prußischen Freien und Bauern in der Propstei Samland über ihre Mißhelligkeiten ${ }^{36}$. Ob Paul von Rusdorf mit Städten und Ritterschaft nach dem Eingang der Antworten über diese auf Ständeversammlungen weiterhin ausführlich beraten hat, ist unklar ${ }^{37}$. Die Bemühungen des Hochmeisters beflügelten den Karthäusermönch Heinrich Beringer zu den wunderbarsten Hoffnungen. Dy teufele yn der bellen wurden bey langer zceyt ny also mortlich irschrecket und dem bilgen orden und dem armen lande ny so grose genode bedacbt. Gelinge die Besserung des Landes, würde das Preußenland von Gott vor Polen, Heiden, Ketzern und

32 So gibt die „Ermahnung des Karthäusers“, eine 1428 abgefaßte, an den Hochmeister gerichtete Schrift des nicht näher bekannten Karthäusermönchs Heinrich Beringer die Anfrage Pauls von Rusdorf wieder. Abdruck der Schrift in: Scriptores rerum Prussicarum, hrsg. v. Theodor Hirsch, Max Töppen, Ernst Streblke, Bd. 4 (Leipzig 1870, Ndr. Frankfurt am Main 1965) 448-465, das Zitat 455, vgl. a. 453. Bei Danzig erkundigte sich der Hochmeister danach, warum die leute auch merklichen an irer wolfart und guttern abnemen und von was sachen das volk so merklichen abnimpt. AST 1, Nr.343. Die Stadt Mohrungen wurde aufgefordert zu berichten, yn welcherleye materie daz sich daz irloufft, das daz lant abenympt. OBA 4503.

33 AST 1, Nr.343.

34 OBA 4503.

35 OBA 4507.

${ }^{36}$ OBA 4512. Möglicherweise sind auch die Klagen von Land und Städten des Gebietes Balga und diejenigen der Gewerke der Neustadt Thorn (AST 1, Nr.344-345) in diesem Zusammenhang entstanden.

37 In seinem Brief vom 18. Februar 1427 an den Hochmeister hält der Bischof von Ermland eine neue Landesordnung für sinnvoll, wenn man gemeynen rath doruff bette, als is wol vor eynem jar gewogen wart. AST 1, Nr.366. Ob er sich damit nur auf die Umfrage des Hochmeisters vom November 1425 oder auf spätere Verhandlungen im Jahr 1426 mit den Ständen bezieht, läßt sich nicht entscheiden. 
allen Feinden beschirmt und sich zu einem Spiegel der ganzen Christenheit entwickeln ${ }^{38}$.

Der Art der hochmeisterlichen Fragestellung, der Benennung konkreter Probleme wie etwa dem Verhältnis von geistlicher und weltlicher Gerichtsbarkeit oder dem Kleiderluxus und den unmäßigen Feierlichkeiten ${ }^{39}$, kann man ablesen, daß der Hochmeister selbst bereits feste Vorstellungen von den Ursachen des Übels hatte. Die Fragen zum sittlichen Lebenswandel der Untertanen führen unmittelbar zur Landesordnung von 1427 hinüber, denn diesem Komplex wird darin breiter Raum gewährt. Außerdem weiß man, daß die Gebietiger des östlichen Preußenlandes, der Komtur von Königsberg, der zugleich Oberster Marschall war, die Komture von Balga und Brandenburg mit Bischof Franz von Ermland am 26. Januar 1427 zu Pr. Eylau über eine neue Landesordnung verhandelt und etliche Artikel zusammengestellt haben ${ }^{40}$ und daß ihr Ergebnis vom Hochmeister anschließend gebilligt und in Kraft gesetzt worden ist ${ }^{41}$. Die Initiative zur Gesetzgebung lag in diesem Fall allein bei der Landesherrschaft. Hochmeister Paul von Rusdorf hat, um den Gebrechen des Landes durch eine „Reformation“42 abzuhelfen, ständische Beratungen über eine neue Landesordnung veranlaßt und sie schließlich auf der Grundlage eines mit dem Bischof von Ermland abgestimmten Gebietigerentwurfes eingeführt. Mit dieser Feststellung über den formalen Verfahrensablauf hat man freilich noch nicht ein Urteil darüber gefällt, wessen Wünsche und Vorstellungen die landesherrlichen Regelungen besonders berücksichtigten.

Die Ordnung von $1427^{43}$ unterscheidet sich in ihrem Inhalt sehr stark von der von 1420. Während man 1420 eine Entwicklung durch eine im Ansatz systematische Kodifikation zum Abschluß bringt, macht man 1427 einen Neuanfang. Die 31 Artikel lassen sich etwa fünf verschiedenen Bereichen zuordnen: christlicher Glaube, Gesinde und Dienstboten, Handwerk, Luxus, Handel. Der christliche Glaube soll dadurch gestärkt werden, daß jeder Gutsinhaber sein Gesinde, insbesondere sein prußisches Gesinde, zum regelmäßigen Kirchgang anhält. Ebenso haben die Schulzen in den deutschen Dörfern bzw. die Kämmerer in den prußischen Dörfern dafür zu sorgen, daß der Feiertag nicht durch alltägliche Arbeit entweiht wird. In einer gewissen Spannung zu solchen Bemühungen stehen die Bestimmungen über das prußische Gesinde, denn ihm wird ausdrücklich untersagt, in den vorwiegend von Deutschen bewohnten Städ-

38 Scriptores (wie A. 32) $453 \mathrm{f}$.

39 Die Sachbereiche, die der Hochmeister in seinem Schreiben an Danzig aufzählt (AST 1, Nr. 343), tauchen auch in den eingereichten Antworten (OBA 4503, 4507, 4512) wieder auf, ohne daß diese sich freilich auf diese Punkte beschränkt hätten.

40 AST 1, Nr.365, 366, 369: ... zu Ylaw, do man die artikel satzt, die artikel czu balden.

11 AST 1, Nr.367, 369: ... als von den artikeln, die euwir genade gesatzet bat czu balden und uns bevolen bat czu gebiten und dozu uffseen zu baben, das man sie balde,... (Komtur von Balga an Hochmeister)

42 Die Klagen der samländischen Freien hat die Hochmeisterkanzlei mit dem Vermerk versehen: reformaciones patrie. OBA 4512.

43 AST 1, Nr. 363 (Fassung für das Ordensland); Nr. 364, Codex diplomaticus Warmiensis, Bd. 4, hrsg. v. Viktor Röbrich, Franz Liedtke, Hans Scbmaucb (Monumenta Historiae Warmiensis 9, Braunsberg 1935) Nr.163 (Fassungen für das Bistum Ermland). 
ten und in den deutschen Dörfern Dienste anzutreten; die Prußen sollen also getrennt von den Deutschen in ihren Siedlungseinheiten leben bleiben. Über diesen Artikel zeigte sich Bischof Franz von Ermland, einer der Konzipienten der Landesordnung, in einem Brief an den Hochmeister wenig beglückt, denn er befürchtete die Folge, das die Preussen in dem gelouben wurden abenemen ${ }^{44}$. Seine Bemerkung zielt darauf ab, daß die Prußen nicht so leicht und nicht so lange mehr an den Resten ihrer heidnischen Sitten und Gebräuche festhalten würden, wenn sie vermischt mit den Deutschen lebten. Aber der Orden berücksichtigte mit der kritisierten Anordnung die Wünsche der prußischen Freien, beschwerten sie sich doch wiederholt darüber, daß das Gesinde wegen der hohen Löhne in den Städten vom Lande dorthin abziehe ${ }^{45}$. Aus der Sicht des Ordens bedeutete die Landflucht der prußischen Jugend, daß auf Dauer die Dienstleistungen der Freien für die Herrschaft gefährdet waren ${ }^{46}$, und daher suchte er die Abwanderung durch eine solche immer wiederholte Verordnung einzudämmen und ihr Einhalt zu gebieten ${ }^{47}$. Die Landesordnung legt ferner für verschiedene Gesindedienste Lohnsätze fest, regelt den freien Ausgang an Sonn- und Feiertagen sowie am Feierabend, beschreibt die Bedingungen für die Beendigung des Dienstverhältnisses. Im Bereich des Handwerkswesens werden den städtischen Bürgermeistern Aufsichtsrechte über die Einhaltung der alten Handwerksgewohnheiten und über die Qualität der Produkte zugestanden. Damit die Arbeit auf den Feldern nicht in Vergessenheit geriet, suchte man die übermäßige Feierei zu beschränken. Hochzeiten dürfen nicht länger als zwei Tage dauern, und zu Kindtaufen dürfen allein die Paten und die allernächsten Verwandten geladen werden, und es wird nur noch eine Mahlzeit zugelassen. Im Bereich des Handels werden völlig unsystematisch Einzelfragen angeschnitten. Der Vorkauf auf dem Lande wird verboten, damit alle Waren auf den Markt kommen. Der Jahrmarkt soll in jeder Stadt nur einmal im Jahr stattfinden. Die Herrschaft darf wie alle anderen frei Getreide auf den Märkten aufkaufen, und schließlich wird ein fester Verkaufspreis für das Bier festgesetzt.

Trotz der Vielfalt der Einzelbestimmungen haben die angeführten Paragraphen wohl in ausreichendem Maße belegt, daß sich der Orden 1427 auf eine bestimmte Lebenswelt konzentriert, auf die Lebensbereiche der unteren Bevölkerungsschichten, auf Bauern, Gesinde, Dienstboten, Handwerker, Kleinhändler, oder, anders ausgedrückt, auf die Lebensumstände des Landes und der Kleinstadt. Es werden ausgespart oder

\footnotetext{
${ }_{44}$ AST 1, Nr.365.

${ }^{45}$ Vgl. z. B. die Klage vor dem Komtur von Balga (AST 1, Nr.344) oder die der samländischen Freien (OBA 4512): Man beachte nicht das Gebot, daß die Prußen den Deutschen nicht in den Städten dienen dürften, sondern bei ihren Vätern bleiben sollten. Wo vorher drei oder vier Personen das Hofgesinde ausgemacht hätten, sei jetzt nur noch eine zurückgeblieben, so daß die Äcker nicht hinreichend bestellt werden könnten.

${ }^{46}$ Auf die Beschwerden der Ehrbarleute, Freien und Bauern seines Gebietes befahl der Komtur von Balga, das keyn Prusse in Dutschen dorffern ader in steten sal dynen ader wonen, went also werden unsere boken und dinste vorwustet und vorterbet, we $/ n]$ sy sich mit den Dutschen mengen. AST 1 , Nr.344.

47 Vgl. Reinhard Wenskus, Der deutsche Orden und die nichtdeutsche Bevölkerung des PreuBenlandes mit besonderer Berücksichtigung der Siedlung, in: Die deutsche Ostsiedlung des Mittelalters als Problem der europäischen Geschichte, hrsg. v. Walter Schlesinger (Vorträge und Forschungen 18, Sigmaringen 1975) 417-438, hier 429.
} 
allenfalls von ferne angedeutet die Wirkungsbereiche der Fernhandel treibenden Kaufmannschaft in den „Hauptstädten“ des Landes und der Ritter und Knechte mit ihren großen Dienstgütern sowie die Konfliktfelder zwischen ihnen und dem Orden. Diese Beobachtung ist mit dem Geltungsbereich der Landesordnung zu erklären, ist sie doch nicht für den gesamten Ordensstaat, sondern nur für den östlichen Teil des Preußenlandes erlassen worden, für das sog. Niederland, d.h. die Komtureien Balga, Brandenburg und Königsberg, für das Ermland und anscheinend auch für das Oberland, zumindest für die Komturei Elbing ${ }^{48}$. In diesen Gebieten bestand kaum eine größere ständische Opposition gegen die Ordensherrschaft; hier hatte der Orden, gerade in den prußischen Kerngebieten und unter den prußischen kleinen Freien, die treuesten Anhänger, die ihm letztlich sein Überleben im 13jährigen Ständekrieg 1454/66 wenigstens im späteren Ostpreußen gesichert haben. Seine größten Feinde besaß er im wirtschaftlich fortgeschritteneren Teil des Landes an der Weichsel, im städtischen Bürgertum der Fernhandelsstädte im allgemeinen, in dem von Thorn im besonderen und in der Ritterschaft des Kulmerlandes ${ }^{49} .1427$ hat der Orden eine Ordnung nur für einen Teil des Gesamtstaates, für die ihm ergebenen Landesteile in Kraft gesetzt. Und er ist darin in manchen Artikeln den Wünschen seiner Anhängerschaft gefolgt, denn die Bestimmungen über das Gesinde entsprechen den Forderungen der kleinen Freien zur Aufrechterhaltung ihrer bäuerlichen Wirtschaft in der Agrarkrise. Aber die Initiative zu dem Gesetzgebungswerk ging vom Orden aus, er versuchte von sich aus regulierend in die Welt seiner Untertanen einzugreifen. Um die Notlage weiter Bevölkerungskreise zu lindern oder zu beseitigen, entschloß sich Hochmeister Paul von Rusdorf, das Leben in Stadt und Land durch Vorschriften, die am gemeinen Nutzen in seinem Verständnis orientiert waren, zu ordnen. Dabei griff er Klagen und Anregungen ständischer Gruppen auf, ohne sich jedoch von ihnen in allem die Richtlinien vorgeben zu lassen. Die Landesordnung von 1427 hat ihre Fortsetzung in den beiden Ordnungen von 1441 und 1444 gefunden, die Hochmeister Konrad von Erlichshausen ebenfalls nur für das östliche Preußenland erlassen hat $^{50}$ und für die dieselbe Interpretation gilt.

${ }^{48}$ Die Ordnung selbst (AST 1, Nr.363) gibt ihren Geltungsbereich nicht an. Sie ist von den Komturen von Königsberg, Balga und Brandenburg verfaßt (AST 1, Nr.365) und in deren Gebieten entsprechend einem Befehl des Hochmeisters auch verkündet worden (AST 1, Nr. 369). Ebenfalls hat sie der Komtur von Elbing in seinem Gebiet eingeführt (AST 1, Nr.367), was der Herausgeber Max Toeppen übersehen zu haben scheint, wenn er von der „Landesordnung der Niederlande“ (AST 1, S.469) spricht. In Verhandlungen über einzelne Artikel der Ordnung empfahl der Bischof von Ermland, die alten Vorschriften für die Wollenweber nicht allein für das Niederland, sondern für das ganze Land zu erneuern (AST 1, Nr.366).

49 Wensk $u$ s (wie A.47) $428 \mathrm{f}$.

so Auf seinem Huldigungsumzug hat der neue Hochmeister Konrad von Erlichshausen am 9. August 1441 die Ordnung von 1427 unverändert, von unbedeutenden redaktionellen Abweichungen abgesehen, für die Gebiete der Bischöfe von Ermland und Samland und der Komture von Königsberg, Balga und Brandenburg, die in der Einleitung ausdrücklich genannt werden, bestätigt. AST 2, Nr.244. Daß erst diese Landesordnung die Artikel 20-31 der älteren von 1427 hinzugefügt habe, wie Toeppen ebd. S. 361 vermutet, trifft nicht zu, da der Bischof von Ermland sich bereits im Februar 1427 offensichtlich auf die Artikel 22 und 30 der Ordnung vom 26. Januar 1427 (Ordensfassung) bezieht. Codex (wie A.43), Nr. 168 = AST 1, Nr.366. Im Oktober 
Diese drei Ordnungen zeigen aber nur die eine Seite der Wirklichkeit des Ordensstaates zwischen 1410 und 1454. Die andere Seite, die Opposition gegen den Orden, machte sich in den 30er und 40er Jahren lautstark bemerkbar, und ihr Interesse richtete sich ebenfalls auf ein neues Gesetzgebungswerk, freilich ganz anderen Inhalts. Denn als Paul von Rusdorf zu Anfang der 30er Jahre wegen des ungeliebten Bündnisses mit Litauen und dem nachfolgenden kurzen Waffengang mit Polen gegenüber den Ständen in die politische Defensive geriet, lebte die Diskussion um ein gud regiment für das gesamte Land, wie es in den Quellen heißt, wieder auf, damit dadurch gemeyne gebrechen und unredlicbkeit abgestellt würden. Als Herrschaft und Stände im November 1432 zur Schlichtung ihrer beiderseitigen Rechtsstreitigkeiten beschlossen, einen jährlichen Richttag abzuhalten, übertrugen sie ihm zugleich die Aufgabe, ein solches Regiment zu erarbeiten ${ }^{51}$. Wer dabei eine vorwärtstreibende Initiative entfalten wollte, läßt sich den Vorstellungen über die Verfahrensform ablesen. Im März 1433 vereinbarten die Städte untereinander, daß jede von ihnen für die Neufassung der Landesordnung die alten Willküren und Schriften des Landes überprüfen, aus ihnen die jedermann nützlichen Bestimmungen ausziehen und auf dieser Grundlage einen schriftlichen Entwurf auf den verabredeten Verhandlungstag mit dem Hochmeister mitbringen solle ${ }^{52}$. Dementsprechend liefen die Verhandlungen auf der Tagfahrt, die wegen des Krieges mit Polen im Sommer 1433 erst am 24. Januar 1434 stattfand, in der Weise ab, daß die Städte und die Ritterschaft gemeinsam dem Hochmeister und seinen anwesenden Gebietigern das Konzept eines neuen Regimentes mit 40 Artikeln übergaben und der Landesherr anschließend dazu positiv oder negativ Stellung nahm ${ }^{53}$. Zwischen der ständischen Fassung von 1434 und der herrschaftlichen Ordnung von 1427 gibt es einen einzigen Bereich, der in beiden behandelt und zugleich in gleichem Sinne geregelt wird, nämlich die Förderung des christlichen Glaubens und die Belebung des kirchlichen Lebens. Ansonsten haben die beiden Stände 1434 gänzlich die Komplexe in den Vordergrund geschoben, die ihr Leben bestimmten, nämlich die Städte den Handel und die Ritterschaft das Dienstgüterrecht, während die Probleme der Handwerker, Bauern und unterbäuerlichen Schichten, auf die sich der Orden 1427 so sehr konzentriert hatte, vollständig außer Betracht blieben.

Die Schwerpunktsetzung von 1434 bedeutete zugleich, daß alle kritischen, strittigen Punkte zwischen der Herrschaft und den Ständen angeschnitten wurden, und es ist daher nicht verwunderlich, daß der Hochmeister etwa zur knappen Hälfte der vorgelegten Artikel ausweichend, mit Vorbehalten oder eindeutig ablehnend antwortete und seine Zugeständnisse minderrangige Fragen betrafen ${ }^{54}$. Zwar sicherte er zu, die Vorrechte der Handel treibenden Ordensdiener vor den städtischen Bürgern bei

\section{Fortsetzung Fußnote von Seite 70}

1444 wiederholte Konrad von Erlichshausen für das Niederland mit Zustimmung der Bischöfe von Ermland und Samland und der Gebietiger und Amtsleute des Niederlandes die Ordnung von 1441 in einer überarbeiteten und ergänzten Fassung. AST 2, Nr.383.

${ }^{51}$ AST 1, Nr. 430-433.

52 AST 1, Nr. 440.

53 AST 1, Nr. 485, 487.

\$4 Vgl. die Zusammenstellung bei Thielen (wie A. 29), $58 \mathrm{f}$. 
Kaufgeschäften und Schuldangelegenheiten einschränken zu wollen, ohne sie allerdings gänzlich aufzuheben. Den Pfundzoll, einen Einfuhrzoll auf alle Waren, aufzuheben, konnte er sich angesichts der Finanzkalamitäten des Ordens nicht entschließen; er überließ die Entscheidung darüber Verhandlungen der Ordensgebietiger mit dem jeweiligen Stadtrat, was faktisch eine Zurückweisung der Forderung bedeutete. Deutlicher äußerte er sich zum städtischen Verlangen, daß fortan bei allgemeinen Getreideausfuhrverboten nicht mehr Sondererlaubnisse für einzelne Personen gegen Zahlung des sog. Lobgeldes an den Orden gewährt werden sollten. Wegen des Zugriffs auf die Ordenskasse erwiderte Paul von Rusdorf, das desir artikel trifft dy birschaft an, und ist dorumb in forder bedacbt genomen. Keinen rechten Anklang fand die Ritterschaft mit ihrem Begehren, daß der Hochmeister die aufgekauften Dienstgüter wieder an Ritter und Knechte ausgeben solle. Paul von Rusdorf erklärte sich lediglich in einer dehnbaren Formulierung dazu bereit, dem Wunsch entsprechend seinem Vermögen entgegenzukommen. Seitdem der Orden infolge der Wandlungen im Militärwesen weniger auf die schweren Reiterdienste der Ritterschaft als vielmehr auf größere Einnahmen zur Bezahlung von Söldnern Wert legte, kaufte er systematisch die Dienstgüter der großen Freien auf und gab sie anschließend an Bauern mit der Verpflichtung zu Zinsund Naturalabgaben wieder aus ${ }^{55}$. Demselben Zweck diente es, wenn er Güter nicht mehr zu kulmischem, sondern zu magdeburgischem Recht verlieh, weil bei letzterem die Vererbung auf männliche Nachkommen und Seitenverwandte beschränkt, somit die Möglichkeit des Rückfalls an die Herrschaft wesentlich größer war und dieser auBerdem beim Erbfall ein Teil der Fahrhabe zustand. Die Ritterschaft forderte daher für die neue Landesordnung, solche Güter an Verwandte, sofern welche überhaupt vorhanden seien, vererben zu dürfen, stieß damit jedoch auf die Ablehnung des Ordens ${ }^{56}$. Ebensowenig ließ die Herrschaft von der Verpflichtung ab, daß man sein Getreide in den herrschaftlichen Mühlen mahlen lassen mußte; das bis dahin bewahrte Mühlenregal wollte sie sich auch fernerhin entgegen der ständischen Forderung nach einer Aufhebung bewahren. Wenn die neue Landesordnung in Kraft gesetzt sein würde, sollte sie, gestand Paul von Rusdorf zu, fortan nicht vom Orden allein aus eigener Machtvollkommenheit, etwa durch einen neuen Hochmeister, sondern nur nach Beratung mit Land und Städten abgeändert werden dürfen.

Die Tagfahrt vom 24. Januar 1434 deckte auf, daß die Vorstellungen von Herrschaft und Ständen über die Inhalte eines neuen Regimentes für das Land weit auseinanderklafften. Sobald man daran ging, das Verhältnis beider Seiten in grundsätzlicheren Fragen in rechtliche Regeln zu fassen, ließ sich nicht mehr verbergen, daß die starken gegensätzlichen Interessen den Abschluß eines Kompromisses nicht zuließen. Es ist kaum zu leugnen, daß manche ständischen Forderungen in ihrer Konsequenz die Substanz der Ordensherrschaft antasteten, dadurch, daß sie Einnahmequellen für deren ohnehin geschwächte Finanzen verstopften und sie damit in noch größere Abhängigkeit von der ständischen Steuerbewilligung gebracht hätten. In diesem Umstand dürfte begründet liegen, daß die gesetzgeberischen Bemühungen von 1433/34 an-

55 Wenskus (wie A.6) $376 \mathrm{f}$.

${ }^{56}$ Allgemein zur Auseinandersetzung um das Dienstgüterrecht in der ersten Hälfte des 15. Jahrhunderts vgl. Boockmann, (wie A. 27) 64-76. 
scheinend völlig folgenlos versandet sind ${ }^{57}$. Der Rezeß vom 24. Januar 1434 führt zwar die Antworten des Hochmeisters zu jedem Artikel des ständischen Entwurfs auf, aber eine auf dieser Grundlage erarbeitete Neufassung der Landesordnung ist nicht überliefert, sie hat es vermutlich niemals gegeben, denn die Verhandlungen sind auf späteren Tagfahrten nicht fortgeführt oder irgendwann einmal wieder aufgenommen worden. Wahrscheinlich haben beide Parteien die Absicht zu einer schriftlichen Fixierung aufgegeben, als sie erkannten, daß sie ihre wesentlichen Ziele gegen den Widerstand der anderen Seite nicht würden durchsetzen können ${ }^{58}$.

Erst ein Jahrzehnt später, in der Zeit des Hochmeisters Konrad von Erlichshausen (1441-1449), nahmen die Verhandlungen über ein neues Regiment wieder breiten Raum ein 59 . Dabei trifft man allerdings auf eine andere Parteienkonstellation als in den 30er Jahren, nicht mehr auf das Gegenüber von Orden auf der einen, Städten und Ritterschaft auf der anderen Seite, sondern auf das Gegenüber der Städte, unterstützt von einem Teil der Ritterschaft, und dem anderen Teil der Ritterschaft und auf den zwischen beiden Richtungen schwebenden und schwankenden Hochmeister. Der Wandel rührt daher, daß andere Inhalte die Debatte belebten, Fragen des Handels und des Marktes, an denen sich die unterschiedlichen Interessen von manchen Rittern und Knechten und der großen Fernhandelsstädte entzündeten. Uns sollen an dieser Stelle jedoch weniger die inhaltlichen Differenzen als vielmehr die formalen Aspekte beschäftigen. In welcher Weise beabsichtigte man im preußischen Ordensstaat der 1440er Jahre, ein umfassendes Gesetzgebungswerk, dadurch lande und stete, arm und reich, zcunemen und gedeyen mochten ${ }^{60}$, zu verabschieden? Die Konzentration auf die Verfahrensfragen ist auch deswegen von der Sache her gerechtfertigt, weil sich die Verhandlungen auf weite Strecken ausschließlich darum drehten und weil gerade die Städte schließlich erfolgreich versuchten, bewußt über Formfragen den gesamten Gesetzgebungsplan zu hintertreiben, um nicht durch eine breite Diskussion inhaltlicher Streitfragen ihre politische Interessengemeinschaft mit der Ritterschaft gegen den Orden zu gefährden. Um zwei Formalien stritt man sich zu wiederholten Malen. Wer sollte zur Einleitung der Verhandlungen den ersten Entwurf einer neuen Ordnung vorlegen, die Herrschaft oder die Stände? Wer sollte den Entwurf beraten und entscheidungsreif vorlegen, ein kleiner, von wenigen Vertretern der Herrschaft und der Stände besetzter Ausschuß oder eine umfassend besuchte Ständeversammlung mit Vertretern aller großen und kleinen Städte und der Ritterschaften möglichst vieler Gebiete auf der Grundlage des imperativen Mandates?

57 Gegen Erich Weise, Das Widerstandsrecht im Ordenslande Preussen und das mittelalterliche Europa (Veröffentlichungen der niedersächsischen Archivverwaltung 6, Göttingen 1955) 128.

s8 Carl August Lückerath, Paul von Rusdorf (Quellen und Studien zur Geschichte des Deutschen Ordens 15, Bad Godesberg 1969) 144, behauptet, eine interne Opposition im Orden habe wegen der Nachgiebigkeit des Hochmeisters die Durchführung des neuen Regimentes boykottiert; dafür fehlt es jedoch an Belegen.

${ }_{59}$ Zum Folgenden vgl. Max Toeppen, in: AST 2, S.760-763, AST 3, S. 105-109; Klaus Eberhard Murawski, Zwischen Tannenberg und Thorn (Göttinger Bausteine zur Geschichtswissenschaft 10/11, Göttingen 1953) 108-118.

60 Äußerung Konrads von Erlichshausen über das Ziel eines „guten Regimentes“ auf dem Ständetag zu Elbing am 9. Juni 1444, AST 2, Nr.368, S. 594. 
Die Gegensätze traten sogleich mit aller Deutlichkeit zutage, als Konrad von Erlichshausen im Juni 1444 auf einem Ständetag zu Elbing zum ersten Mal das Projekt einer neuen Landesordnung vorstellte und erörtern ließ, nachdem er dazu schon im März 1443 von Vertretern der kulmerländischen Ritterschaft gedrängt ${ }^{61}$ und von diesen sogar verdächtigt worden war, er wolle mit Rücksicht auf die Städte das Vorhaben einschlafen lassen ${ }^{62}$. Entsprechend seiner Einladung zum Ständetag forderte er am 9. Juni 1444 die ständischen Vertreter dazu auf, das ir uns rathen belffet, wie wir in die sachen komen und sie anbeben mogen. Die ständische Antwort trug der Landrichter des Kulmerlandes Simon Glase vor. Er erklärte, das euwir gnade das oberste boupt sey euwirs regiments, und wissen ouch nicht, was gebrechen euwir gnade doranne babe. Daher möge ihnen der Hochmeister seine Verbesserungsvorschläge schriftlich unterbreiten, sie würden dann gern darüber an ihren Heimatorten Verhandlungen pflegen und deren Antworten wieder einbringen. Zur Beschlußfassung auf einer weiteren Tagfahrt sollten auch die kleinen Städte entboten werden, sind es alle anruret, uff das mann denne mit eyntracbt sulche sachen vornemen und vorleiben moge. Im weiteren Verlauf der Verhandlungen bekundeten die Städte durch den Bürgermeister von Kulm, sie hätten keinerlei gebrechen, denn ihre Angelegenheiten würden von den städtischen, alljährlich überprüften und von der Herrschaft bestätigten Willküren ${ }^{63}$ geregelt. Der Landrichter des Kulmerlandes fand mit seiner Haltung Widerspruch unter den eigenen Standesgenossen, denn eine Gruppe von Rittern und Knechte erklärte, sie seien von vierzehn der angesehensten kulmerländischen Ritter in den vergangenen Ostertagen darum gebeten worden, die vielen vorhandenen Beschwerden vorzutragen, denn wenne ir in den steten gedeyet, wir uffm lande mussen vorterben. Den Standpunkt des Ordens vertrat der Bischof von Ermland. Man solle sechs Vertreter der Bischöfe, sechs der Gebietiger, sechs der Ritterschaft und sechs der Städte nehmen, und dieser 24erAusschuß solle die Angelegenheit erörtern und zur endgültigen Beschlußfassung vorbereiten. Ir irkenneth wol, das man im sulchen bawffen, als wo 400 seyn, obel zcu den dingen mogk komen ${ }^{64}$.

Die grundsätzlichen Standorte der verschiedenen Richtungen waren damit deutlich genug bezeichnet, und innerhalb der hier angezeigten Bahnen verliefen auch die Verhandlungen der nächsten Jahre. Den Städten war eine neue Landesordnung überhaupt unerwünscht, weil sie u. U. in innerstädtische Verhältnisse eingegriffen oder für die Beziehung der Städte zum Land antistädtische Regelungen getroffen hätte. Daher beharrten sie auf ihren jeweiligen eigenen Willküren und stellten sich ansonsten mit einem Teil der Ritterschaft auf den scheinbar ganz herrschaftlichen Standpunkt, der Hochmeister selbst solle einen Entwurf erarbeiten und vorlegen, ihn dann aber getreu dem Prinzip „quod omnes tangit, ab omnibus debet approbari“ von den großen und kleinen Städten und von den Ritterschaften aller Gebiete billigen lassen. Damit waren

${ }^{61}$ Ein entsprechender Vorstoß der kulmerländischen Ritterschaft während ihrer Verhandlungen mit dem Hochmeister zu Papau am 21. März 1443 wird 1444 sowohl von seiten der Ritterschaft als auch von seiten des Hochmeisters erwähnt. AST 2, Nr.367; Nr.368, S. 597.

${ }_{62}$ AST 2, Nr.367.

63 Wir haben regiment, das beyssen wilkoer, in euweren steten.

${ }^{64}$ AST 2, Nr.368 (Aufzeichnung der Ordenskanzlei), 369 (städtischer Rezeß). 
aber für die Vollendung des Werkes hohe, nahezu unüberwindliche Hindernisse errichtet. Die Kritik der Interessenten, die bei einem so weit gezogenen Kreis notwendigerweise sich aus den verschiedensten Quellen speisen mußte, würde zuerst auf den Hochmeister und seinen Entwurf einprasseln, und bei einer so großen Zahl von Entscheidungsberechtigten würde bestenfalls der kleinste gemeinsame Nenner als Kompromiß herauskommen und alle für die Städte kritischen Punkte unberührt lassen. Ein Teil der Ritterschaft war jedoch offensichtlich nicht bereit, unter dem Gesichtspunkt der gemeinsamen politischen Opposition von Städten und Ritterschaft gegen die Ordensherrschaft, so wie sie im Preußischen Bund organisiert war, davon abzusehen, daß die Landschaft unter den städtischen Handelsbedingungen und unter der Monopolstellung des städtischen Zwischenhandels litt. Dadurch, daß Konrad von Erlichshausen die neue Landesordnung auf die Tagesordnung der Ständeversammlung setzte, gab er indirekt seine Förderung des Vorhabens zu erkennen, ohne sich freilich dabei allzu sehr in den Konflikt der verschiedenen Gruppen hineinziehen lassen zu wollen. Daher betonte er immer wieder, daß die Stände schon mit eigenen ausgearbeiteten Vorstellungen an ihn herantreten sollten, denn dann hätten sie sich zumindest bis zu einem gewissen Grade schon vorher untereinander auseinandersetzen und abstimmen müssen, und allein ein kleiner Ausschuß schien auf Dauer überhaupt erfolgversprechend, um eine umfassende Ordnung zu erarbeiten. Einen solchen nur aus wenigen Personen bestehenden Ausschuß sagte der Hochmeister dann auch am Ende der Elbinger Tagfahrt zur Fortführung der Angelegenheit nach Martini (11. November) dem angesehenen kulmerländischen Ritter Hans von Logendorf $\mathrm{zu}^{65}$.

Es ist nicht ersichtlich, was den Hochmeister dazu bewogen hat, von dieser Linie abzuweichen und für den Spätherbst 1444 überall im Lande Versammlungen in den ritterschaftlichen Gebieten und in den Städten zur Beratung über das neue Regiment anzusetzen. Im November 1444 riefen zahlreiche Komture und Vögte die Ritter und Knechte in ihren Amtsbezirken zusammen und befragten sie nach ihren Beschwerden und Wünschen ${ }^{66}$. So sollte etwa im Kulmerland zwischen dem 8 . und 22. November jeder Gebietiger in seinem Amtsbezirk mit seiner Ritterschaft über die Landesordnung verhandeln, und anschließend, am 29. November, sollten alle Gebietiger und die Ritterschaft des gesamten Kulmerlandes in Kulmsee zu einer vorläufigen Beschlußfassung sich versammeln ${ }^{67}$. Daß in dem gesamten Komplex nicht nur die Stände, sondern auch der Orden mit Finten arbeitete, mag ein kleines Detail belegen. Der Komtur von Thorn bat den Hochmeister darum, ihm als Grundlage für die Verhandlungen mit der Ritterschaft eine Abschrift der alten Ordnung zuzuschicken. Die Stände wollten sich auf wenige Artikel beschränken, damit diese dann umso sicherer eingehalten würden. Darumbe, fügte der Komtur hinzu, ab euwir gnade etwas vunde in den alden ussaczungen, das widder euwir gnade were, das mocbte euwir [gnade] czuvor ustilligen und ustbun, uff daz es nicht qweme vor ougen ${ }^{68}$. Die von einigen ständischen Versammlungen überlieferten Forderungen gehen, wie nicht anders zu erwarten, sehr

65 AST 2, Nr. 372.

66 AST 2, Nr.385-397.

67 AST 2, Nr.385.

68 Ebd. 
weit auseinander und widersprechen einander zum Teil, insbesondere soweit es Handelsfragen betrifft, in erheblichem Maß. Auf diesem Wege war eine Einigung, das war offensichtlich geworden, nicht zu erreichen.

Vielleicht unter dem Eindruck dieser Erfahrung kehrte Konrad von Erlichshausen zu seiner alten Linie zurück, indem er auf dem Ständetag zu Elbing am 30. April 1445 die Anwesenden dazu aufforderte, aus jedem Landesteil einige Vertreter zur Beratung und Abfassung eines Regimentes zu wählen, wen durch vyl bowpt eyn sulchs nicht wol beslossen moge werden, wenne die sachen grosz seyn. Diesmal stimmten die Stände einem Ausschuß zu, aber die Opposition verstand es trotzdem, ihn in seiner Wirkung zu entschärfen. Das Gremium, bestehend aus zwei Vertretern der Bischöfe, zweien der Gebietiger, fünf der Ritterschaft und fünf der Städte, sollte am 22. Mai in Frauenburg zusammentreten und auf der Grundlage von Entwürfen, die jede Seite schriftlich oder mündlich einzubringen hatte, ein Regiment beschließen, unter der inhaltlichen Vorgabe, das nymands an seynen privilegien, recbten und willekoren zcu nae gegangen wurde. Die Vereinbarung des Ausschusses trat jedoch nicht sogleich in Kraft, sondern sie sollte anschließend erst von den ständischen Vertretern mit ihren städtischen Gemeinden bzw. den ritterschaftlichen Gebietsversammlungen erörtert werden und mit deren möglichen Verbesserungsvorschlägen auf einer allgemeinen Tagfahrt des Landes mit Zustimmung aller beschlossen werden, danach jedoch aber auch nur zunächst versuchsweise in Kraft gesetzt werden ${ }^{69}$.

Auf dieser langen Wegstrecke wurde, soweit man aus den Quellen erkennen kann, nur die erste Station, der Zusammentritt des Ausschusses, überhaupt erreicht. Wenn auch ein Verhandlungsprotokoll nicht vorliegt, so gibt doch der überlieferte städtische Entwurf einer Landesordnung mit seinen 53 Artikeln genügend Aufschluß über die städtischen Intentionen ${ }^{70}$. Sie beinhalten von seiten des Ordens auch Zugeständnisse geradezu verfassungsrechtlicher Natur. Der Hochmeister darf nicht mehr Kriege eröffnen, Bündnisse und Friedensverträge abschließen mit anderen Mächten ohne Wissen und Willen der Stände; er soll damit in aller Form seine Autonomie in der Außenpolitik verlieren. Ein abgeschlossener oder niedergeschlagener Prozeß darf von keinem Amtsträger des Ordens wieder eingeleitet werden; es wird also dem Orden das Evokationsrecht abgesprochen. Im Handelsbereich kehrt die städtische Forderung wieder, daß bei allgemeinem Getreideausfuhrverbot niemand gegen Entrichtung des Lobgeldes eine Exportlizenz erhalten darf. In den Streitfragen zwischen Städten und Ritterschaft wird der Monopolanspruch der preußischen Städte auf den Zwischenhandel wiederholt. So wird etwa der Nümberger Handelsbetrieb auf zwei Jahrmärkte in Danzig und Marienburg beschränkt, und den „Gästen“, d.h. den ausländischen Kaufleuten, wird untersagt, die Wochenmärkte der kleinen Städte aufzusuchen, so daß diese also nur den einheimischen Kaufleuten offenstehen. Im allgemeinen verfolgt der

69 AST 2, Nr. 404 (Aufzeichnung der Ordenskanzlei), 405 (städtischer Rezeß).

${ }^{70}$ AST 2, Nr.410. Zur Beurteilung der Überlieferung vgl. Klaus Neitmann, Die preußischen Stände und die Außenpolitik des Deutschen Ordens vom I. Thorner Frieden bis zum Abfall des Preußischen Bundes (1411-1454), in: Ordensherrschaft, Stände und Stadtpolitik, hrsg. v. Udo Arnold (Schriftenreihe Nordost-Archiv 25, Lüneburg 1985) 25-79, hier 73 A. 43 (gegen Murawski [wie A. 59] 113). 
Entwurf die Tendenz, die Handelsstellung der großen Städte gegenüber den nachteiligen Wünschen mancher Kreise der Ritterschaft zu bewahren, ohne durch überspannte Forderungen die Ritterschaft zu besonderem Widerstand zu reizen. Den Städten kam es erneut darauf an, die Gegensätze zwischen beiden Gruppen herunterzuspielen, damit die Verbundenheit beider Seiten gegen den Orden, dokumentiert in der Selbsthilfeorganisation des Preußischen Bundes, nicht einer allzu starken Belastungsprobe ausgesetzt wurde.

Nach der Tagung des Ausschusses sind anscheinend die weiteren vorgesehenen Maßnahmen und Schritte gar nicht erst eingeleitet worden, denn man erfährt nichts von weiteren Verhandlungen über die Landesordnung in den einzelnen Gebieten und Städten. Erst im Juni 1446 wurde wieder der zu Frauenburg behandelten Punkte gedacht. Städte und Ritterschaft wünschten, daß aus den damals vom Ausschuß vereinbarten Artikeln die fünf oder sechs nützlichsten ausgesucht und zur weiteren Beratung an die Ältesten in den jeweiligen Gebieten und Städten überwiesen würden, wieder mit dem ausgesprochenen Vorbehalt, das nymandes dorinne zcu nabe werde gegangen. Mit anderen Worten: Der Landesordnung sollten dadurch alle politischen Zähne gezogen werden, daß man alle potentiellen Streitpunkte zwischen den Ständen aussparte. Man wollte der Landesherrschaft unbedingt verwehren, bei der Ausarbeitung eines umfassenden Regimentes die Gegensätze zwischen den Ständen anzuheizen und zu ihren eigenen Gunsten auszunutzen. Selbst wenn Konrad von Erlichshausen eine solche Absicht verfolgt haben sollte, gab er sie jetzt auf, indem er dem ständischen Verlangen zustimmte ${ }^{71}$.

Die Jahre $1448 / 49$ bewiesen ihm nochmals, daß die Landesgesetzgebung sich nicht zum Kampf gegen die im Preußischen Bund vereinigte ständische Opposition instrumentalisieren ließ, indem er bei den Verhandlungen über eine neue Ordnung die gegensätzlichen wirtschaftlichen Interessen von Städten und Ritterschaft aufeinanderprallen ließ. Auf Drängen der kulmerländischen Ritterschaft berief der Hochmeister wegen ihrer Klagen gegen die großen Städte eine Ständeversammlung nach Elbing auf den 14 . November 1448 ein $^{72}$ und legte dort mit den anwesenden Rittern und Knechten neun Artikel zur Regelung wirtschaftlicher Streitfragen vor, die deren Wünschen entgegenkamen. U.a. wurde die Seefahrt für jedermann freigegeben; Verbote sollten nur mit ausdrücklicher Zustimmung der Landesherrschaft und beider Stände ausgesprochen werden. Das bedeutete, daß der Getreideexport grundsätzlich zugelassen war und damit auch der ausländischen Konkurrenz der Holländer und Engländer offenstand, wovon sich die Ritterschaft eine Preissteigerung für ihre Produkte versprach. Außerdem wurde jedermann der freie Zugang zum städtischen Wochenmarkt gestattet. Damit stand sowohl den ausländischen Kaufleuten als auch den Prälaten und Gebietigern der Weg offen, so daß die Ritterschaft ebenfalls ihre Waren teurer zu verkaufen hoffen durfte. Die städtischen Ratssendeboten lehnten es jedoch unumwunden ab, den neun Artikeln zuzustimmen, da sie dazu nicht bevollmächtigt seien. Sie sicherten lediglich zu, die Ordnung ihren heimischen Gemeinden zur Beratung vorzulegen.

71 AST 2, Nr.440, S.713.

72 AST 3, Nr. 42. 
Konrad von Erlichshausen fand zwar zu ihrem Verhalten harte Worte. Er habe in den Artikeln das Beste des Landes erkannt und verlange daher, daß sie eingehalten würden, wente ber were eyn berre der lande $e^{73}$. Die Nachgeschichte enthüllte jedoch, daß er seinem großen Wort nicht die entsprechenden Taten folgen zu lassen vermochte. Der Oberste Marschall riet ihm bereits im Dezember 1448, er solle den Artikel über den freien Wochenmarkt fallen lassen, da die Städte darin ihr Verderben sähen und sie ihn auf gar keinen Fall billigten ${ }^{74}$. Der unnachgiebige städtische Wille wurde einige Monate später in einer markanten Äußerung sichtbar: Nimmer würden Ritter und Knechte noch deren Kinder den Tag erleben, an dem eine solche Marktordnung gelten würde ${ }^{75}$. Vor solch entschlossenem Widerstand wich der Hochmeister zurück. Geradezu kleinmütig klangen seine Worte am 1. Januar 1449 zu den städtischen Vertretern: Man habe doch den Artikel der Ritterschaft zugesagt; wie könne man ihn jetzt wieder abändern? Sein Vorschlag, ihn wenigstens versuchsweise für ein Jahr einzuführen, stieß ebensowenig auf Gegenliebe, so daß Konrad das Vorhaben schließlich gänzlich fallen lie $\beta^{76}$. Mit dieser Entscheidung war die kulmerländische Ritterschaft auf Dauer nicht einverstanden. Im Herbst 1449 erinnerte sie den Landesherrn an die neun Artikel des neuen Regimentes vom November 1448 und forderte, daß die beiden zentralen Punkte, die freie Seefahrt und der freie Wochenmarkt, in Kraft gesetzt würden. Als der Hochmeister ausweichend antwortete, drohte sie ihm damit, sich mit den Ritterschaften der anderen Landesteile zu versammeln und mit ihr über Abhilfe zu beraten ${ }^{77}$. Unter dem neuen, im März 1450 gewählten Ordensoberhaupt Ludwig von Erlichshausen verlagerte sich die politische Kontroverse auf andere Felder, trieb die Auseinandersetzung zwischen Orden und Ständen rasch ihrem Höhepunkt zu, bis sich der Preußische Bund 1454 von Hochmeister und Orden lossagte und damit das Land in einen 13jährigen Bürgerkrieg stürzte.

Zwei Wochen vor seinem Tode hatte Konrad von Erlichshausen noch erleben müssen, daß er von den Gegensätzen zerrieben zu werden drohte ${ }^{78}$. Dadurch, daß er eine neue Landesordnung auf die Tagesordnung setzte, waren zwar, wie er wohl in seinem Kalkül gehabt hatte, Fernhandelsstädte und Ritterschaften mehrfach hart aufeinander gestoßen, aber gerade deswegen vermochte der Hochmeister als Mittler keinen Ausgleich zu stiften. Stattdessen machte ihn jede Seite dafür verantwortlich, daß er ihre Forderungen nicht vorbehaltlos durchsetzte. Er war sich wohl der Gefahren bewußt, die der Herrschaft aus spannungsgeladenen Beratungen über eine neue Landesordnung erwachsen konnten; darauf deutet hin, daß er solche Verhandlungen wiederholt nur zögend und auf Drängen der Ritterschaft oder Teilen davon zuließ und sich bei ihnen nach Möglichkeit mit einer eigenen klaren Richtungsvorgabe zurückhielt. Allein der Umstand, daß er so vorsichtig taktierte, belegt schon die Macht und das Selbstbewußtsein der beiden ständischen Gruppen zumindest in den 1440er Jahren.

73 AST 3, Nr. 44.

74 AST 3, Nr. 47.

${ }^{75}$ AST 3, Nr. 56, S. 102.

76 AST 3, Nr. 51.

77 AST 3, Nr.56.

${ }^{78}$ So Murawsi (wie A. 59) 118; ähnlich Toeppen, in: AST 3, S.111. 
Wenn der Hochmeister gegen den deutlich bekundeten Widerstand der Städte die Einführung einer neuen Landesordnung für den gesamten Ordensstaat, sei der Wunsch dazu auch mehr von ihm oder von der Ritterschaft ausgegangen, nicht durchzusetzen vermochte, kommt man nicht umhin, daraus eine Schlußfolgerung für die Beurteilung der innenpolitischen Lage zu ziehen. Sicherlich ist es aufschlußreich, die Vorstöße des Ordens gegen die ständischen Ansprüche auf Mitherrschaft zu untersuchen. Ebenso notwendig ist es aber auch zu fragen, wieviel Rechte die Stände eigentlich noch der Ordensherrschaft belassen wollten, und zu analysieren, wie sie deren Betätigungsfelder und Entscheidungsmöglichkeiten immer weiter einschränk$\operatorname{ten}^{79}$.

Die vorstehenden Darlegungen haben sich darauf beschränkt, an Hand einiger Beispiele das Mit- und Gegeneinander von Herrschaft und Ständen in den Verhandlungen über und an der Abfassung verschiedener Landesordnungen in der Phase zwischen ihrem Aufkommen im letzten Viertel des 14. Jahrhunderts bis hin zum Zerfall des alten Ordensstaates in der Mitte des 15. Jahrhunderts herauszustellen. Es dürfte deutlich geworden sein, daß die Landesordnungen $\mathrm{zu}$ den großen Themen auf den Tagfahrten des Ordens mit Städten und Ritterschaften gehörten und daß sie dem Zusammenwirken beider Seiten ihre Entstehung verdankten. Daß die Herrschaft sie mit „Rat“ der Stände in Kraft gesetzt hat, kann geradezu als konstitutiv für sie gelten. Aus seinem Überblick über die Gesetzgebung der europäischen Länder vom 13. bis zum 15. Jahrhundert folgerte Armin Wolf 1973: „Die Form der Übereinkunft zwischen Herrscher und Optimaten (Ständen) erscheint im späten Mittelalter als Normalfall der Gesetzgebung "80. Diesem „Normalfall“ kann man den preußischen Ordensstaat ohne Einschränkung zuordnen. Der Orden hat immer wieder und regelmäßig mit seinen Ständen über die Inhalte neuer Landesordnungen sowohl aus eigenem Antrieb als auch auf deren Initiative hin verhandelt, er hat die Ordnungen nicht einseitig kraft eigener Autorität erlassen, so daß man ihn zumindest unter dem Gesichtspunkt unseres Themas nicht als grundsätzlich ständefeindlich wird hinstellen können ${ }^{81}$. Die zen-

${ }^{79}$ Etwas einseitig scheint mir z.B. Marian Biskup in seinen Forschungen über das Verhältnis von Orden und Ständen im 15. Jahrhundert nur den ersten Gesichtspunkt hervorzuheben, z. B. Die Rolle des Deutschen Ordens in Preußen in der Geschichte Polens, in: Deutschland, Polen und der Deutsche Orden (Sonderdruck aus dem Internationalen Jahrbuch für Geschichts- und Geographieunterricht 16/1975, dort nicht erschienen) 19-29, hier 25-27; Die Rolle der Städte in der ständischen Repräsentation des Ordensstaates Preußen im XIV. und XV. Jahrhundert, in: Preußenland 15 (1977) 55-69, hier 63-65.

${ }^{80}$ Wolf (wie A. 7) 543. Janssen (wie A. 11 ) 26 betont, „daß die mittelalterlichen Territorialgesetze, trotz der autokratischen Attitüde des verwendeten Vokabulars ... keineswegs Ausfluß eines nach eigenem Ermessen frei entscheidenden, mit $Z$ wangsgewalt ausgerüsteten Herrscherwillens sind, sondern das Ergebnis einer Übereinkunft zwischen dem Landesherrn ... und qualifizierten Landsassen, eben den Landständen“. Zum Rechtsgrund der ständischen Beteiligung vgl. Helmut Freiwald, Der Plan Herzog Albrechts vom 2. August 1525 zur Vereinigung und rechtlichen Umgestaltung der drei Städte Königsberg, in: Jahrbuch der Albertus-Universität zu Königsberg/Pr. 11 (1961) 153-172, hier $169 \mathrm{f}$.

${ }^{81}$ Auch die Entstehungsgeschichte der Landesordnungen widerlegt das Urteil Biskups, (Preußenland 15 (1977) 56), daß die Ordensbehörden „den Einfluß der Stände ... auf die staatlichen Angelegenheiten nicht von sich aus ermöglichten“. Der Orden hat sich einer Beratung mit den 
trale Kategorie der Quellen, der Rat, ist dabei am besten dazu geeignet, das für ein gültiges Ergebnis notwendige Zusammenwirken von Herrschaft und Ständen auszudrücken. Moderne Begriffe setzen leicht falsche Akzente, wenn etwa Armin Wolf für die Zeit bis 1410 die Gesetzgebungsgewalt allein dem Orden zuschreiben ${ }^{82}$ oder wenn Erich Weise nach 1414 dem Orden nur noch die Exekutive zugestehen will ${ }^{83}$.

Dabei muß man sich allerdings im klaren darüber sein, daß sich hinter der allgemeinen Formulierung von der gemeinsamen Beratung im konkreten Einzelfall ganz unterschiedliche Verhältnisse verbergen. Denn Herrschaft und Stände bilden keine unwandelbaren monolithischen Blöcke, sondern der Hochmeister muß sowohl auf die Gebietiger als auch auf die Bischöfe Rücksicht nehmen, und unter den Ständen sind sich Städte und Ritterschaft bzw. einzelne Gruppen unter ihnen mit ihren Auffassungen und Zielen durchaus nicht immer einig, so daß in den Beratungen gelegentlich die gegensätzlichen Vorstellungen mit aller Wucht aufeinanderprallten. Die ausgewählten Einzelfälle haben hinreichend belegt, daß Herrschaft und Stände unter unterschiedlichen Voraussetzungen und in wandelbaren Konstellationen miteinander und gegeneinander um die Abfassung von Landesordnungen gerungen haben ${ }^{84}$. Ihr Charakter und ihre Schwerpunkte hingen davon ab, von wem die Initiative ausging und inwieweit er seine Ziele durchzusetzen vermochte. Ganz unterschiedliche Themenbereiche wurden für die Ordnungen vorgesehen, je nach dem, welche Gruppe ihre Interessen durch eine verbindliche Regelung bekräftigt sehen wollte. Die verschiedenen Beteiligten setzten unterschiedliche Akzente; diese im Einzelfall näher zu bèstimmen, wird die zentrale Aufgabe der weiteren Forschung sein. Dafür ergeben sich m. E. zwei Schlußfolgerungen.

1. Der Untersuchung wird ein Vergleich einzelner sachlich zusammengehöriger Bestimmungen in der beachtlichen Reihe der Landesordnungen zugrunde gelegt. Denn es gibt eine große Zahl von Sachkomplexen, die in Einzelverordnungen oder größeren Kodifikationen immer wieder auftauchen. Dabei wandeln sich die Bestimmungen, werden verändert, ergänzt oder verkürzt, fallen zeitweise ganz weg, werden später wieder aufgenommen. Man muß sich daher ständig fragen, was die Veränderungen bedeuten und auf wen sie wohl zurückgehen. Dabei ist das Quellenmaterial insgesamt so ergiebig, daß man dabei nicht nur auf den Text der Ordnungen allein angewiesen ist dann wäre man für die Frage nach dem Urheber letztlich zu sehr auf Vermutungen angewiesen -, sondern auch Unterlagen über begleitende Verhandlungen sowohl von

\section{Fortsetzung Fußnote von Seite 79}

Ständen über die Landesordnungen niemals entzogen, der Streit ging immer nur um die jeweiligen Rechte beider Seiten. Manche Verordnungen über innerstädtische Angelegenheiten, etwa über die Handwerker, sind vom Hochmeister erst auf Verlangen der städtischen Ratssendeboten erlassen worden.

82 Wolf (wie A.7) 754. Wolfs Darstellung übersieht an dieser Stelle, daß das große Kapitel oder der Hochmeister zwat allein die Regeln, Gesetze und Gewohnheiten der Ordenskorporation änderten, aber über Verordnungen für das Leben in Stadt und Land mit ständischen Vertretern berieten.

${ }^{83}$ Weise (wie A. 57) 93. Dazu mit Recht kritisch Tbielen (wie A. 29$) 46$.

${ }^{84}$ Unter diesem Gesichtspunkt hat Dralle (wie A. 10) 136-140 die späteren Landesordnungen zwischen 1466 und 1497 sehr gut analysiert. 
seiten der Stände als auch von seiten der Herrschaft heranziehen kann. Dieser Ansatz ist hier nicht näher verfolgt worden, er verspricht aber, wie anderswo gezeigt werden soll, reichen Ertrag.

2. Zur Analyse der Einzelbestimmungen tritt die Gesamtbewertung der großen zusammenfassenden Landesordnungen, sowohl derjenigen, die verabschiedet, in Kraft gesetzt und - mehr oder weniger - befolgt worden sind, als auch derjenigen, die über das Stadium der Verhandlungen und des Entwurfs nicht hinaus gediehen sind. Berücksichtigt man beides, öffnet man sich zugleich die Augen für das elementare Problem, warum die Beschlußfassung in dem einen Fall geglückt ist und in dem anderen nicht. Andernfalls beschwört man die Gefahr von Fehlurteilen über die Gesamtentwicklung herauf, indem man nur auf die geltenden Ordnungen achtet, ohne sich um die besonderen Bedingungen für ihre Geltung zu kümmern ${ }^{85}$.

Letztlich wird man wieder zu der zentralen Frage geführt, wer eine Landesordnung insgesamt oder in Teilen in ihrem Charakter bestimmt hat, welche Interessen darin ihren Niederschlag gefunden haben. Denn da der Landesherr die Ordnungen nicht kraft souveräner Machtvollkommenheit setzt, sondern sie mit Rat seiner Stände erläßt, kann man an ihnen zugleich die jeweilige konkrete Kräfteverteilung zwischen Herrschaft und Ständen bzw. einzelnen ständischen Gruppen ablesen. Welche der divergierenden Bestrebungen sich durchsetzte, hing auch immer von der allgemeinen politischen Situation ab. Daß dabei zwischen der Zeit vor und nach 1410 ein tiefgehender Unterschied bestand, braucht nicht besonders betont zu werden. Die Verhandlungen der 30er und 40er Jahre des 15. Jahrhunderts zeigen ein labiles Gleichgewicht zwischen Herrschaft und Ständen insofern, als keine Seite gegen den deutlichen Widerstand der anderen ihren Willen in Gestalt einer verabschiedeten Landesordnung durchzusetzen vermochte, so daß wegen der gegenseitigen Paralysierung zumindest umfassendere Gesetzgebungswerke nicht mehr zustande kamen.

Die Landesordnungen haben sicherlich auf Dauer tief in das soziale Leben eingegriffen und es, zumal mit ihrer zunehmenden Differenzierung und Erfassung weiterer Lebensbereiche, wesentlich mitbestimmt. Die Reglementierung des alltäglichen Daseins gipfelt schließlich in der Polizeigesetzgebung der frühen Neuzeit mit ihren zuweilen karikaturenhaften Zügen ${ }^{86}$. Dafür kann man jedoch nicht allein die fürstlichen Obrigkeiten und ihren Wunsch nach Ausdehnung ihrer Zuständigkeiten und Zugriffsmöglichkeiten auf die Untertanen verantwortlich machen. Daß auch die Stände und ständische Gruppen wesentliche Anstöße zu dieser Entwicklung gegeben haben, haben meine Ausführungen am preußischen Beispiel hoffentlich belegen können.

${ }^{85}$ Vgl. etwa das Urteil Dralles (A. 10).

${ }^{86}$ Hans Maier, Die ältere deutsche Staats- und Verwaltungslehre (München ${ }^{2} 1980$, Tb. 1986) 74-91. Territoriales Beispiel: Reiner Schulze, Die Polizeigesetzgebung zur Wirtschafts- und Arbeitsordnung der Mark Brandenburg in der frühen Neuzeit (Untersuchungen zur deutschen Staats- und Rechtsgeschichte N.F. 22, Aalen 1978). 
